\title{
Optical Gamification (OG); Serial Versus Random Model to Improve Pre-Service Physics Teachers' Concept Mastery
}

\author{
https://doi.org/10.3991/ijet.v15i09.11779 \\ Saprudin Saprudin $\left({ }^{-}\right)$ \\ Universitas Pendidikan Indonesia, Bandung, Indonesia \\ Universitas Khairun, Ternate, Indonesia \\ saprudin@unkhair.ac.id \\ Liliasari Liliasari, Andhy Setiawan \\ Universitas Pendidikan Indonesia, Bandung, Indonesia \\ Ary Setijadi Prihatmanto \\ Institut Teknologi Bandung, Bandung, Indonesia
}

\begin{abstract}
OpticalGamification (OG) is an information and communication technology (ICT)-based gamification-application that applies the elements of game design in a serious context of optics. Through setting for the variations in pre-service physics teachers' (PPTs) access to the sub-topics presented in this application, two OG application models are generated, namely: 1) serial model; designed to facilitate PPTs who study sequentially, and 2) random models; designed to facilitate PPTs who study randomly depends on their choices. This research is quasi-experimental with pretest-posttest nonequivalent multiple group design involving 48 PPTs enrolled in wave and optics course, specifically on the topics of interference and diffraction. The results of this research indicate that there is no significant difference in the improvement of PPTs' concept mastery in the serial and random groups. Both of these models can be used as references in designing ICT-based gamification-applications for a more effective and efficient learning in the future.
\end{abstract}

Keywords-OpticalGamification (OG), Serial Model, Random Model, Concept Mastery.

\section{Introduction}

Gamification is the use of game design elements in non-game contexts $[1,2,3]$. The implementation of gamification has had a positive impact in various sectors of society such as transportation [3, 4, 5, 6, 7, 8], healthcare [9, 10, 11, 12], economics and business [13, 14, 15, 16], disaster risk management [17], parenting [18], and the education sector [19, 20, 21, 22, 23, 24]. 
In the education sector, previous research found a successful implementation of gamification in blended learning $[21,25,26,27,28,29,30,31,32,33,34,35,36$, 37]. Other research indicates a similar success in conventional learning [38, 39], elearning [40, 41, 42, 43, 44, 45, 46, 47, 48, 49, 50], and learning through massive open online courses $[51,52,53,54,55,56,57,58,59]$.

In general, research related to the implementation of gamification in learning are more focused on the research of how the impact of gamification in changing student behavior, so they are motivated to learn $[27,35,50,60,61,62,63,64,65,66,67]$, and more engaged in learning activities [20, 21, 25, 28, 31, 32, 60, 62, 63, 65, 68, 69]. Through the improvement in motivation and engagement, student learning outcomes was proven empirically to be improved $[70,71]$. One of the learning outcomes is the students' concept mastery.

A concept is a mentality that represents one class of stimulus [72]. Concept can also be interpreted as labeling of objects, symbols, or events with the same characteristics or important attributes [73]. Concept can be acquired in two ways, namely: a) concept formation; acquisition of concepts before students learn about material in a formal education situation, and b) concept assimilation; acquisition of concept during and after learning in a formal education [74]. The theory of meaningful learning by Ausubel states that meaningful learning is a process of relating new information to relevant concepts that already exist in a person's cognitive structure [74]. The most optimal concept development can take place if the most general or inclusive elements of a concept are introduced first, then the more detailed and more specific elements of the concept are given afterward [72, 74]. Therefore, to develop a good curriculum, concept analysis is needed. Certain relationships between the concepts are analyzed so that the most general and the more specific concepts can be identified [72, 75]. In contrast to learning in universities, the population in this research are PPTs over 18 years old, where they can be categorized as an adult [76, 77, 78]. Some assumptions used in adult education (andragogy) include, 1) self-concept; the shift from a person who is dependent on others towards an independent person, 2) experience; humans accumulate a lot of experiences they have acquired so that they become a source of learning that develops, 3) readiness for learning; humans are increasingly oriented to the task of developing the social role they carry, and 4) orientation towards learning; the perspective of time changes from knowledge with delayed application to knowledge with immediate application, and changes in learning orientation from learning-centered to problem-centered [76]. One implication of these assumptions is that in learning andragogy, students should be involved in diagnosing their learning needs. Students will feel engaged and motivated to learn if what will be learned is in accordance with their learning needs. [76].

OpticalGamification (OG) is an ICT-based gamification-application that applies elements of game design in a serious context of optics. This application is intended for a wave and optics course, especially on the topic of interference and diffraction. This topic was chosen because it is one of the topics that is still lacking in competency achievement [79]. The setting of variations in PPTs' access to sub-topics of interference and diffraction material is intended to facilitate the diverse ways of learning. For example, PPTs' can study in sequence or randomly. ICT-based gamification- 
application allows learning to be presented without the constraints of space and time, performs an automatic assessment, provides an opportunity to do an unlimited number of evaluations, allows the setting of PPTs' freedom to access, and records the history of PPTs' exploration while participating in learning through the application. The impact of variations in PPTs 'access to learning sub-topics presented in the OG application towards PPTs' concept mastery is an interesting study. Variations in PPTs 'access are closely related to PPTs' behavior when studying the sub-topics presented in the OG application. Studies like this are still rarely found in previous studies. The lack of research on the matter comes a big question related to whether the variations in PPTs' learning behavior that studies the sub-topics presented in the OG application will affect PPTs concept mastery.

OG consists of nine sub-topics and three evaluations, each sub-topic is designed into levels that must be passed by PPTs. Each sub-topic is presented through a virtual laboratory designed in the form of a dependent experimental quiz; which is a quiz that can only be done well if PPTs conduct the experiments through virtual simulations. Meanwhile, the evaluation contains questions in the form of multiple choices. Each level and evaluation has a minimum score limit to get stars as rewards. OG is presented in three sessions, each session consists of three levels and one evaluation. OG is also presented in two models, which are serial and random models. In the OG with serial model, PPTs can learn more than one sub-topic sequentially in the same order of work arrangements for each session. Whereas in the OG with random model, PPTs can learn several sub-topics in random order at each session, they can learn several sub-topics by cross-session randomly of their choosing.

This article aims to discover the empirical evidence related to the comparison of the usage of OG applications in serial and random models towards the PPTs' concept mastery on the topics of interference and diffraction. Empirical evidence found in this research is expected to be used as a reference in designing ICT-based gamificationapplications for future research.

\section{$2 \quad$ Methodology}

\subsection{Research Design and Research Method}

The research used quasi-experimental method with a pretest-posttest nonequivalent multiple group design [80].

\begin{tabular}{cccc}
\hline Group & $\begin{array}{c}\text { Pretest } \\
\text { (dependent variable) }\end{array}$ & Experimental Variable & $\begin{array}{c}\text { Posttest } \\
\text { (dependent variable) }\end{array}$ \\
\hline $\mathrm{G}_{1}$ & $\mathrm{O}_{1}$ & OG with serial model & $\mathrm{O}_{2}$ \\
$\mathrm{G}_{2}$ & $\mathrm{O}_{3}$ & OG with random model & $\mathrm{O}_{4}$ \\
\hline & \multicolumn{3}{c}{ six weeks' instruction } \\
\end{tabular}

Fig. 1. Research Design 


\subsection{Participant}

This research involved 48 PPTs enrolled in the course of waves and optics, especially on the topics of interference and diffraction. Participants were divided into two groups without randomization, experiment group 1 (total $=26 \mathrm{PPTs}, \mathrm{M}=6, \mathrm{~F}=20$, average age $=19$ years old) and experiment group 2 (total $=22 \mathrm{PPTs}, \mathrm{M}=6, \mathrm{~F}=16$, average age $=19$ years old). The characteristics of participants in this research have low motivation and are less engaged in the learning process. Most PPTs stated that majoring in physics department was the second choice when they took the college entrance selection test.

\subsection{Procedure}

The OG application consists of nine sub-topics designed in the form of nine levels and three evaluations. Each sub-topic at each level is presented through a virtual laboratory designed in the form of a dependent experimental quiz. Evaluations are presented in the form of multiple-choice questions. The OG with serial and random models are presented in three sessions, each consisting of three levels and one evaluation. Evaluation 1 (E1) contains material from level 1 (L1), level 2 (L2) and level 3 (L3). Evaluation 2 (E2) contains material from level 4 (L4), level 5 (L5), and level 6 (L6). Evaluation 3 (E3) contains material from level 7 (L7), level 8 (L8), and level 9 (L9). Rewards in the form of stars will be obtained by PPTs if the score obtained is $\geq 70 \%$ of the ideal score for each level and evaluation. L1 presents the sub-topic of lightwave characteristics (ideal score $=75$; time $=15$ minutes; red star reward). L2 presents the sub-topic of the principle of superposition of waves (ideal score $=25$; time $=25$ minutes; orange star reward). L3 presents the sub-topic of double slit interference part 1 (ideal score $=75$; time $=75$ minutes; yellow star reward). $L 4$ presents a sub-topic of double slit interference part 2 (ideal score $=40$; time $=40$ minutes; green star reward). L5 presents the sub-topic of multiple slit interference (ideal score $=40$; time $=40$ minutes; blue star reward). L6 presents the sub-topic of single slit diffraction (ideal score $=50$; time $=50$ minutes; indigo star reward). $\mathrm{L} 7$ presents the sub-topic of circular aperture diffraction (ideal score $=115$; time $=115$ minutes; violet star reward). L8 presents the sub-topic of diffraction grating (ideal score $=95$; time $=95$ minutes; white star reward). L9 presents the sub-topic of resolving power (ideal score $=55$; time $=55$ minutes; black star reward). For each evaluation has an ideal score of 100 .

In the OG with serial model, the learning material is divided into three sessions. Each session consists of three levels (sub-topics) and one evaluation. In the first week, all PPTs followed the pretest and explanation related to the learning mechanism through the OG application. In the second week, PPTs take part in learning session 1 which consists of L1, L2, L3, and E1. Each level can only be done once, while each evaluation can be done repeatedly and become a prerequisite for entering the next session. PPTs conduct learning in sequence with each session. PPTs are required to pass evaluation 1 with a minimum score of 70 to be able to proceed to the next session. The second and third sessions were carried out using the same mechanism as in the first session. PPTs can proceed to the third session when they passed the first and 
second sessions. After completing the learning process through the OG application, PPTs may take posttest.

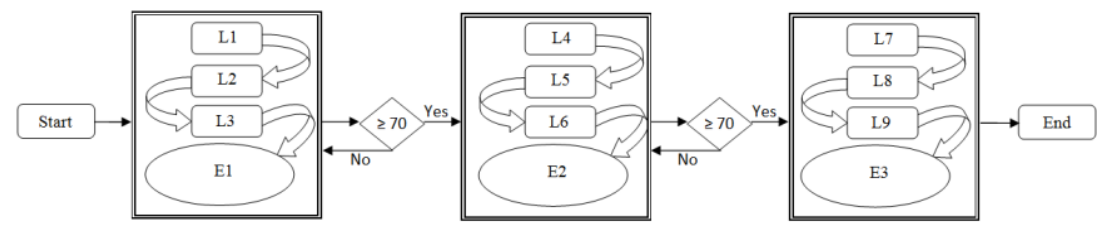

Fig. 2. OG with Serial Model

In the OG with random model, PPTs can learn several levels (sub-topics) in random order on each session and PPTs are also allowed to do cross-sessions. PPTs are also given the freedom to choose the level or evaluation in any session of their choosing. PPTs are successful in following all learning process through the OG application when PPTs can get scores of $\geq 70$ for all evaluations.

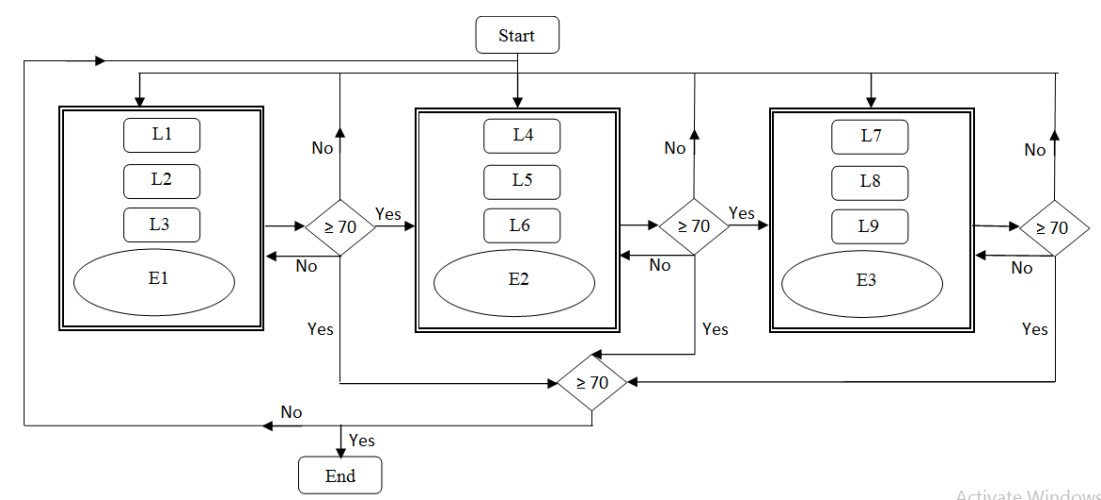

Fig. 3. OG with Random Model

The learning program using OG application is carried out within six weeks with one face-to-face session each week. The design of the learning setting uses blended learning model as shown in Table 1. 


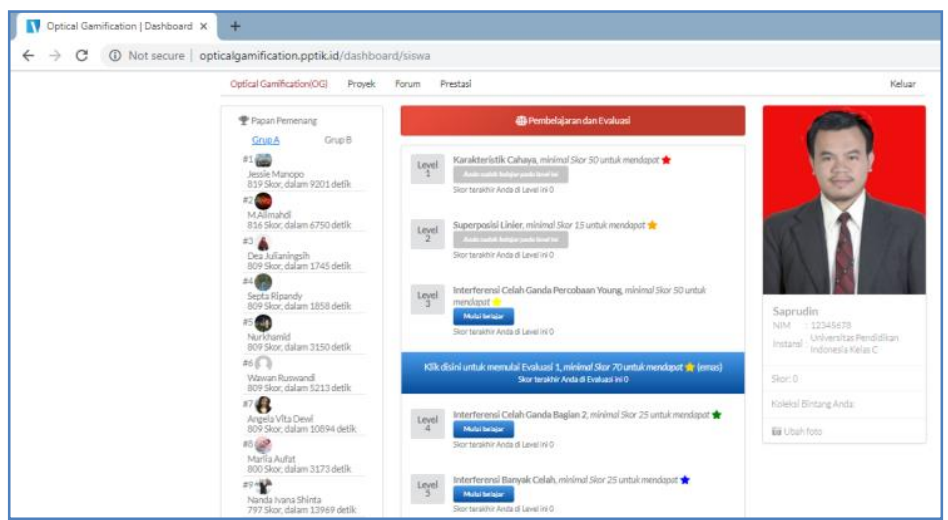

Fig. 4. The Interface of OG application (http://opticalgamification.pptik.id/)

Table 1. Learning Settings for the Topics of Interference and Diffraction

\begin{tabular}{|c|c|c|c|}
\hline \multirow{2}{*}{ Week } & \multirow{2}{*}{$\begin{array}{c}\text { Face-to-Face } \\
\text { (Serial and Random Group) }\end{array}$} & \multicolumn{2}{|c|}{ Online (OG Application) } \\
\hline & & Serial Group & Random Group \\
\hline 1 & $\begin{array}{l}\text { Pretest } \\
\text { Learning mechanism through } \\
\text { OG application }\end{array}$ & L1, L2, L3 and E1 & $\begin{array}{l}\text { L1, L2, L3, L4, L5, L6, L7, } \\
\text { L8, L9, E1, E2, and E3 (cho- } \\
\text { sen randomly by PPTs) }\end{array}$ \\
\hline 2 & $\begin{array}{l}\text { Discussion L1, L2, and L3 } \\
\text { Strengthening mathematics } \\
\text { aspect L1, L2, and L3 }\end{array}$ & $\begin{array}{l}\text { PPTs scoring; } \\
\text { E1 }<70, \text { may retake E1. } \\
\text { E1 } \geq 70 \text { may continue to L4, L5, } \\
\text { L6, E2. }\end{array}$ & $\begin{array}{l}\mathrm{L} 1, \mathrm{~L} 2, \mathrm{~L} 3, \mathrm{~L} 4, \mathrm{~L} 5, \mathrm{~L} 6, \mathrm{~L} 7, \\
\mathrm{~L} 8, \mathrm{~L} 9, \mathrm{E} 1, \mathrm{E} 2 \text {, and E3 (cho- } \\
\text { sen randomly by PPTs) }\end{array}$ \\
\hline 3 & $\begin{array}{l}\text { Discussion L4, L5, L6 } \\
\text { Strengthening mathematics } \\
\text { aspect L4, L5 and L6 }\end{array}$ & $\begin{array}{l}\text { PPTs scoring; } \\
\text { E1 }<70, \text { may retake E1. } \\
\text { E2 }<70, \text { may retake E2. } \\
\text { E1 } \geq 70 \text { may continue to L4, L5, } \\
\text { L6, E2. } \\
\text { E1 and E2 } \geq 70 \text { may continue to } \\
\text { L7, L8, L9, E3. }\end{array}$ & $\begin{array}{l}\text { L1, L2, L3, L4, L5, L6, L7, } \\
\text { L8, L9, E1, E2, and E3 (cho- } \\
\text { sen randomly by PPTs) }\end{array}$ \\
\hline 4 & $\begin{array}{l}\text { Discussion L7, L8, L9 } \\
\text { Strengthening mathematics } \\
\text { aspect L7, L8, L9 }\end{array}$ & $\begin{array}{l}\text { PPTs scoring; } \\
\text { E1 }<70, \text { may retake E1. } \\
\text { E2 }<70, \text { may retake E2. } \\
\text { E1 } \geq 70 \text { may continue to L4, L5, } \\
\text { L6, E2. } \\
\text { E1 and E2 } \geq 70 \text { may continue to } \\
\text { L7, L8, L9, E3. } \\
\text { E3 }<70, \text { may retake E3. }\end{array}$ & $\begin{array}{l}\text { L1, L2, L3, L4, L5, L6, L7, } \\
\text { L8, L9, E1, E2, and E3 (cho- } \\
\text { sen randomly by PPTs) }\end{array}$ \\
\hline 5 & Project & $\begin{array}{l}\text { PPTs scoring; } \\
\text { E1 }<70, \text { may retake E1. } \\
\text { E2 < 70, may retake E2. } \\
\text { E1 } \geq 70 \text { may continue to L4, L5, } \\
\text { L6, E2. } \\
\text { E1 and E2 } \geq 70 \text { may continue to } \\
\text { L7, L8, L9, E3. } \\
\text { E3 }<70, \text { may retake E3. } \\
\text { Uploading projects' report and } \\
\text { documentations }\end{array}$ & $\begin{array}{l}\text { L1, L2, L3, L4, L5, L6, L7, } \\
\text { L8, L9, E1, E2, and E3 (cho- } \\
\text { sen randomly by PPTs) } \\
\text { Uploading projects' report and } \\
\text { documentations }\end{array}$ \\
\hline 6 & Posttest & $\begin{array}{l}\text { PPTs may take the posttest if all le } \\
\text { OG application are passed }\end{array}$ & earning processes in \\
\hline
\end{tabular}




\subsection{Data gathering and data analysis technique}

Data related to PPTs' concept mastery on the topic of interference and diffraction were collected through tests consisting of 50 multiple-choice questions. The improvement of PPTs' concept mastery is calculated by determining the score of normalized gain $\langle\mathrm{g}\rangle[81]$. Normalized gain is interpreted to be in the high category if $(\langle\mathrm{g}\rangle) \geq$ 0.70 , the medium category if $0.70>(\langle\mathrm{g}\rangle) \geq 0.30$, and the low category if $(\langle\mathrm{g}\rangle)<0.30$. An inferential statistical test is performed to discover the presence or absence of significant differences in the improvement of PPTs' concept mastery in using OG with serial and random model.

\section{$3 \quad$ Finding and Discussions}

\subsection{Profile of PPTs' concept mastery}

The results of the pretest and posttest of the PPTs' concept mastery on the topics of interference and diffraction that have been processed using SPSS 16.0 is shown in Table 2 .

Table 2. The Mean, Standard Deviation, and Statistical Test Results from Pretest and Posttest Scores of PPTs' Concept Mastery

\begin{tabular}{|l|c|c|c|c|}
\hline \multirow{2}{*}{\multicolumn{1}{|c|}{ Statistical Test }} & \multicolumn{2}{c|}{ Pretest } & \multicolumn{2}{c|}{ Posttest } \\
\cline { 2 - 5 } & $\begin{array}{c}\text { Serial } \\
\text { Group }\end{array}$ & $\begin{array}{c}\text { Random } \\
\text { Group }\end{array}$ & $\begin{array}{c}\text { Serial } \\
\text { Group }\end{array}$ & $\begin{array}{c}\text { Random } \\
\text { Group }\end{array}$ \\
\hline Ideal Score & 54.00 & 54.00 & 54.00 & 54.00 \\
\hline Mean & 5.04 & 7.50 & 22.85 & 26.64 \\
\hline Deviation Standard & 2.44 & 2.69 & 5.79 & 5.11 \\
\hline One-Sample Kolmogorov-Smirnov Test (Sig.) & 0.412 & 0.577 & 0.811 & 0.361 \\
\hline Test of Homogeneity of Variances & $\mathrm{F}=11.054 ;$ Sig. $=0.812$ & $\mathrm{~F}=5.672 ;$ Sig.= 0.639 \\
\hline t-test (Independent Sample Test) & $\mathrm{t}=-3.325 ;$ Sig.= $=0.002$ & $\mathrm{t}=-2.381 ;$ Sig. $=0.021$ \\
\hline
\end{tabular}

Table 2 shows that the PPTs' concept mastery has improved in both serial and random groups. The t-test results showed that before participating in the learning process, the PPTs' concept mastery between serial and random groups was significantly different. Similar with the PPTs' concept mastery after participating in the learning process. To compare the improvement of PPTs' concept mastery in the two groups, the mean score of normalized gain $\langle\mathrm{g}\rangle$ in the two groups can be used for that purpose [81].

\subsection{Comparison of OG with serial and random model on the improvement of PPTs' concept mastery}

The improvement in the PPTs' concept mastery for each interference and diffraction sub-topics both in serial and random groups is shown in Figure 5. In general, there is no significant difference in the improvement of PPTs' concept mastery on the 
topic of interference and diffraction between PPTs who take part in the learning process by using OG with serial and random model. Statistical test results related to differences in PPTs' concept mastery in the two groups are shown in Table 3.

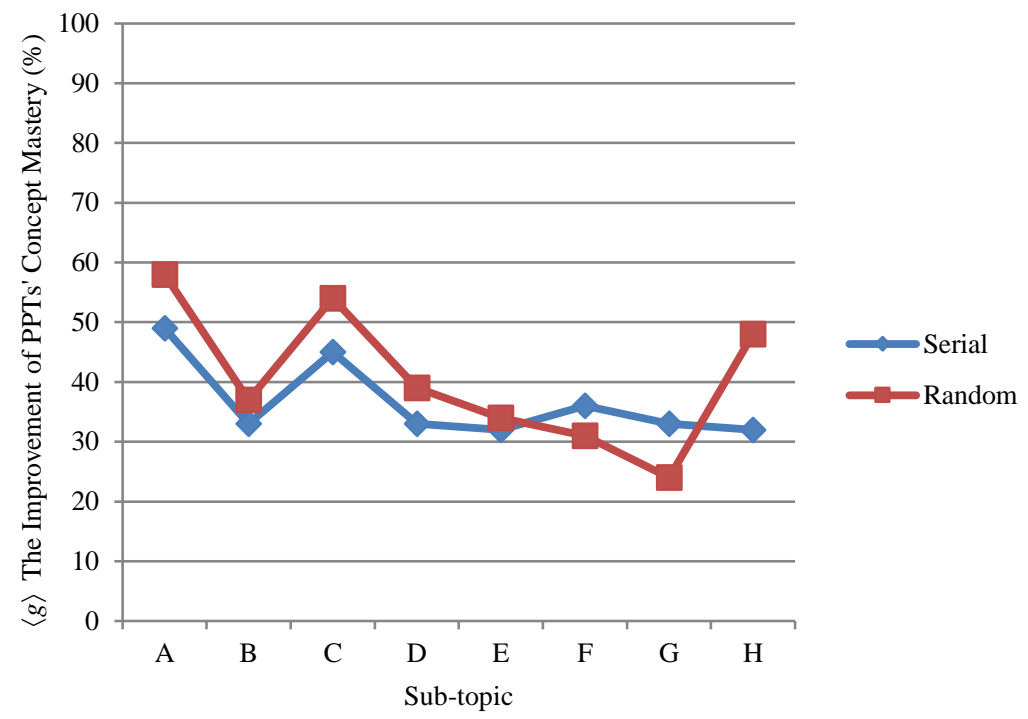

Fig. 5. Comparison of the Improvement of PPTs' Concept Mastery in Serial and Random Group

Table 3. The Test Results of Normality, Homogeneity, and t-test between Serial and Random Groups

\begin{tabular}{|l|c|c|c|c|c|}
\hline \multirow{2}{*}{ Sub-Topic } & \multicolumn{2}{|c|}{$\begin{array}{c}\text { One-Sample Kolmogorov- } \\
\text { Smirnov Test (Sig.) }\end{array}$} & \multirow{2}{*}{$\begin{array}{c}\text { Levene's } \\
\text { test }\end{array}$} & \multicolumn{2}{c|}{$\begin{array}{c}\text { t-test } \\
\text { (df = 46) }\end{array}$} \\
\cline { 2 - 3 } \cline { 6 - 6 } & Serial Group & Random Group & $($ Sig.) & $t$ & Sig. \\
\hline Sub-Topic A & 0.393 & 0.279 & 0.768 & -.974 & 0.335 \\
\hline Sub-Topic B & 0.398 & 0.462 & 0.815 & -.544 & 0.589 \\
\hline Sub-Topic C & 0.608 & 0.827 & 0.841 & -1.317 & 0.194 \\
\hline Sub-Topic D & 0.073 & 0.569 & 0.621 & -.610 & 0.545 \\
\hline Sub-Topic E & 0.513 & 0.560 & 0.424 & -.385 & 0.702 \\
\hline Sub-Topic F & 0.725 & 0.315 & 0.903 & .577 & 0.567 \\
\hline Sub-Topic G & 0.837 & 0.468 & 0.483 & 1.748 & 0.087 \\
\hline Sub-Topic H & 0.822 & 0.721 & 0.195 & -2.074 & 0.044 \\
\hline Topic & 0.679 & 0.596 & 0.819 & -1.496 & 0.141 \\
\hline
\end{tabular}

On sub-topic A (lightwave characteristics), PPTs are asked to; 1) compare and contrast the characteristics of light and sound waves, 2) define terms related to the characteristics of light and sound waves, and 3) employing and reacting to fallacy labels related to the characteristics of light and sound waves. The improvement of PPTs' concept mastery in serial group $(\langle\mathrm{g}\rangle=0.49)$ and random group $(\langle\mathrm{g}\rangle=0.58)$ can be 
categorized as "medium". The improvement of PPTs' concept mastery in the random group is greater than the serial group, but the results of the t-test shows that this difference is not significant.

On sub-topic B (the principle of superposition of waves), PPTs are asked to; 1) compare and contrast the phases of a two-wave propagation graph, 2) provides a reason to why a constructive interference occurs in two interfering coherent waves, 3 ) mention the examples of points where constructive interference occurs from a graph of two-wave superposition, and 4) employing and reacting to fallacy labels related to the frequency and amplitude of the results of two-wave superposition. The improvement of PPTs' concept mastery in serial group $(\langle\mathrm{g}\rangle=0.33)$ and random group $(\langle\mathrm{g}\rangle=$ 0.37 ) can be categorized as "medium". The improvement of PPTs' concept mastery in the random group is greater than the serial group, but the statistical test results show that this difference is not significant.

On sub-topic C (double slit interference), PPTs are asked to; 1 ) develop ideas related to the concept of interference and the path difference of the two-wave that can produce constructive interference, 2 ) provides reasons related to the path difference of the two-wave so that constructive interference can occur, 3) generalize the relationship between the distance of two sequenced bright fringes with the distance between two slits, 4) determine logical actions to enlarge the distance between two adjacent bright or dark fringes, and 5) apply the principle of double slit interference to determine the distance between two adjacent bright fringes and determine the magnitude of the wavelength used in double slit interference. The improvement of PPTs' concept mastery in serial group $(\langle\mathrm{g}\rangle=0.33)$ and random group $(\langle\mathrm{g}\rangle=0.37)$ can be categorized as "medium". The improvement of PPTs' concept mastery in the random group is greater than the serial group, but the statistical test results show that this difference is not significant.

On sub-topic D (multiple slit interference), PPTs are asked to; 1) generalize mathematical models to determine the total number of secondary maxima and minima between two adjacent primary maxima, 2) give various interpretations of the intensity graph (I) to the magnitude of the angle $(\theta)$. The improvement of PPTs' concept mastery in serial group $(\langle\mathrm{g}\rangle=0.33)$ and random group $(\langle\mathrm{g}\rangle=0.39)$ can be categorized as "medium". The improvement of PPTs' concept mastery in the random group is greater than the serial group, but the statistical test results show that this difference is not significant.

On sub-topic E (single slit diffraction), PPTs are asked to; 1) mention some alternative actions to enlarge the distance of two adjacent dark fringes in a single slit diffraction experiment, 2) mention the similarities and differences between Fraunhofer and Fresnel diffraction, 3) develop or enrich the ideas of others related to the concept of a single slit diffraction, and 4) express many ideas related to efforts to increase the distance between two adjacent dark fringes on the screen, 5) record the data information based on the scheme of single slit diffraction experiment presented, 6) apply the acceptable principle in determining the width of the slit on a single slit diffraction, 7) mention examples and non-examples relating to the phase difference $(\beta)$ that produces the minimum intensity, and 8) employing and reacting to fallacy labels related to the result data of the single slit diffraction experiment. The improvement of PPTs' 
concept mastery in serial group $(\langle\mathrm{g}\rangle=0.32)$ and random group $(\langle\mathrm{g}\rangle=0.34)$ can be categorized as "medium". The improvement of PPTs' concept mastery in the random group is greater than the serial group, but the results of the t-test shows that this difference is not significant.

On sub-topic F (circular aperture diffraction), PPTs are asked to; 1) develop or enrich other people's ideas related to the concept of circular aperture diffraction, 2) generalize the mathematical models to determine the magnitude of the first dark ring radius on a circular aperture diffraction, 3) apply the acceptable principle to determine the radius of the dark ring based on the results of practicum data, and 4) apply the concept or principle to determine the magnitude of the wavelength used in a circular aperture diffraction experiment. The improvement of PPTs' concept mastery in serial group $(\langle\mathrm{g}\rangle=0.36)$ and random group $(\langle\mathrm{g}\rangle=0.31)$. The improvement of PPTs' concept mastery in the serial group is greater than the random group, but the statistical test results shows that this difference is not significant.

On the sub-topic $\mathrm{G}$ (diffraction grating), PPTs are asked to: 1) give reasons related to the colors that are most strongly stretched and the reasons why the central color spectrum is white if polychromatic light is passed on a grating, 2) formulate alternative solutions to enlarge the distance between two adjacent dark fringes and determine which diffraction grating can be used to separate the sodium doublet in a particular order, 3) employing and reacting to fallacy labels related to the data of experiment results on the diffraction grating, 4) record the data based on the sketches of diffraction grating experiment presented, and 5) determine the magnitude of the grating constant and the number of bright fringes captured on the screen in the diffraction grating experiment. The improvement of PPTs' concept mastery in the serial group can be categorized as "medium" $(\langle\mathrm{g}\rangle=0.33)$, while the random group can be categorized as "low" $(\langle\mathrm{g}\rangle=0.24)$. The improvement of PPTs' concept mastery in the serial group is greater than the random group, but the results of the t-test shows that this difference is not significant.

On the sub-topic H (resolving power), PPTs are asked to; 1) provides various interpretations of a graph of experiments related to Rayleigh criteria, 2) develop ideas related to the concept and mathematical models of resolving power, 3) determine the maximum distance of two objects that can still be separated by the observer's eye at a certain distance, 4) determine the maximum distance of the observer so that the two objects can still be separated by the eye at a certain distance, and 5) employing and reacting to fallacy labels related to the phenomenon of separating two spectral lines from different isotopes using a spectrometer. The improvement of PPTs' concept mastery in the serial group $(\langle\mathrm{g}\rangle=0.32)$ and random group $(\langle\mathrm{g}\rangle=0.48)$ can be categorized as "medium". The improvement of PPTs' concept mastery in the random group is greater than the serial group. The PPTs' concept mastery in the random group was significantly increased compared to the serial group.

\subsection{Discussion}

In the serial group, all PPTs have the same learning behavior in studying the subtopics of interference and diffraction presented in the OG application. PPTs begin 
studying sub-topics in each level sequentially and ending by an evaluation on each session. PPTs who are categorized as slow learners require a relatively long time to complete the tasks on each session. OG application provides an unlimited opportunity to repeat each evaluation as much as PPTs' choosing so that they can complete the learning program within a predetermined period. For the learning process in the serial group to run well, the lecturer needs to exercise control continuously and keep giving motivation to PPTs so that they want to keep trying and study harder to complete the tasks on each session. PPTs learning behavior is shown in Figure 6(a), which starts from L1 $\rightarrow \mathrm{L} 2 \rightarrow \mathrm{L} 3 \rightarrow \mathrm{E} 1 \rightarrow \mathrm{L} 4 \rightarrow \mathrm{L} 5 \rightarrow \mathrm{L} 6 \rightarrow \mathrm{E} 2 \rightarrow \mathrm{L} 7 \rightarrow \mathrm{L} 8 \rightarrow \mathrm{L} 9 \rightarrow$ E3

In the random group, PPTs are given the freedom to work on the level and evaluation in any session and cross-sessions are also allowed. The analysis result of the PPTs' exploration history show that the learning behavior in studying the sub-topics of interference and diffraction presented in the OG application is very diverse. Each PPTs has a different way of learning from one another. Figures 6(b), 6(c) and 6(d) show how the three samples of PPTs studied in the random group. The first sample is shown in Figure 6(b) that learns starting from E1 $\rightarrow \mathrm{L} 1 \rightarrow \mathrm{E} 1 \rightarrow \mathrm{L} 2 \rightarrow \mathrm{L} 3 \rightarrow \mathrm{E} 1 \rightarrow$ $\mathrm{L} 4 \rightarrow \mathrm{L} 5 \rightarrow \mathrm{L} 6 \rightarrow \mathrm{E} 1 \rightarrow \mathrm{E} 2 \rightarrow \mathrm{L} 7 \rightarrow \mathrm{L} 8 \rightarrow \mathrm{L} 9 \rightarrow \mathrm{E} 3 \rightarrow \mathrm{E} 2 \rightarrow \mathrm{E} 1 \rightarrow \mathrm{E} 2 \rightarrow \mathrm{E} 1 \rightarrow$ $\mathrm{E} 2 \rightarrow \mathrm{E} 3 \rightarrow \mathrm{E} 2 \rightarrow \mathrm{E} 3$. The second sample is shown in Figure 6(c) that learns starting from $\mathrm{L} 1 \rightarrow \mathrm{L} 2 \rightarrow \mathrm{L} 5 \rightarrow \mathrm{E} 1 \rightarrow \mathrm{L} 4 \rightarrow \mathrm{E} 2 \rightarrow \mathrm{E} 3 \rightarrow \mathrm{E} 2 \rightarrow \mathrm{E} 3 \rightarrow \mathrm{E} 1 \rightarrow \mathrm{E} 2 \rightarrow \mathrm{E} 3 \rightarrow$ $\mathrm{L} 3 \rightarrow \mathrm{E} 1 \rightarrow \mathrm{L} 6 \rightarrow \mathrm{L} 7 \rightarrow \mathrm{L} 8 \rightarrow \mathrm{L} 9 \rightarrow \mathrm{E} 3$. While the third sample is shown in Figure $6(\mathrm{~d})$ that learns starting from L1 $\rightarrow \mathrm{L} 2 \rightarrow \mathrm{L} 4 \rightarrow \mathrm{L} 5 \rightarrow \mathrm{L} 6 \rightarrow \mathrm{E} 1 \rightarrow \mathrm{L} 7 \rightarrow \mathrm{L} 8 \rightarrow$ L9 $\rightarrow \mathrm{L} 3 \rightarrow \mathrm{E} 3 \rightarrow \mathrm{E} 1 \rightarrow \mathrm{E} 2 \rightarrow \mathrm{E} 3$.

The setting for freedom of PPTs' access at every level (sub-topic) and evaluation has resulted in the OG application with serial and random models. Although PPTs in the two groups show different behaviors in learning the sub-topics presented, all PPTs can complete the learning program within a predetermined time. The analysis showed that there is no significant difference in the improvement of PPTs' concept mastery between two groups.

Research with relevant finding was also found in the context of sports education, namely research related to contextual interference (CI) effects on learning outcomes in the psychomotor domain. $\mathrm{CI}$ is the memory and performance disruption (i.e., interference) that is resulted from performing multiple skills or variations of skill within the context of practice [82]. There are three variations of the exercise model including the blocked, serial, and random models [83]. Several researches have shown the effect of CI on badminton service skills [83], basketball skills [84], swimming skills [85], and golf skills [84, 86]. The random group showed better performance than the blocked group, and the serial group showed parallel performance with the random group in learning three badminton services [83]. In golf, random model practice can be beneficial for skill acquisition even when the skill or skills to be learned use the same motor programme [86]. The random group also showed a more structured change in mental representation that was more similar to professional golfers compared to the blocked group [87]. 
Paper-Optical Gamification (OG); Serial Versus Random Model to Improve Pre-Service Physics...

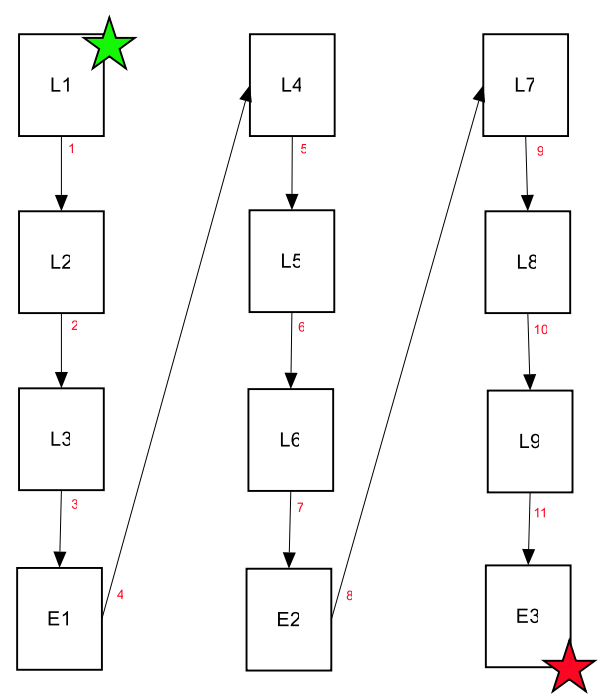

6(a)

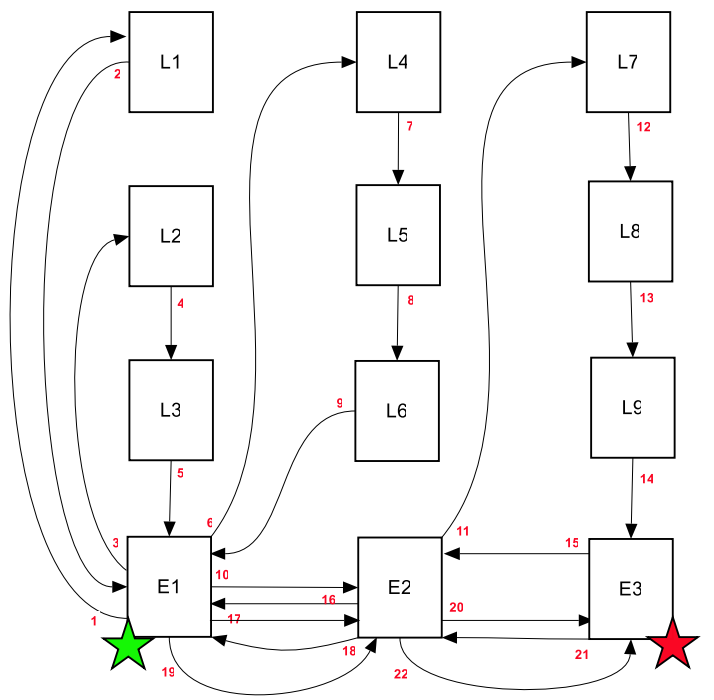

6(b) 


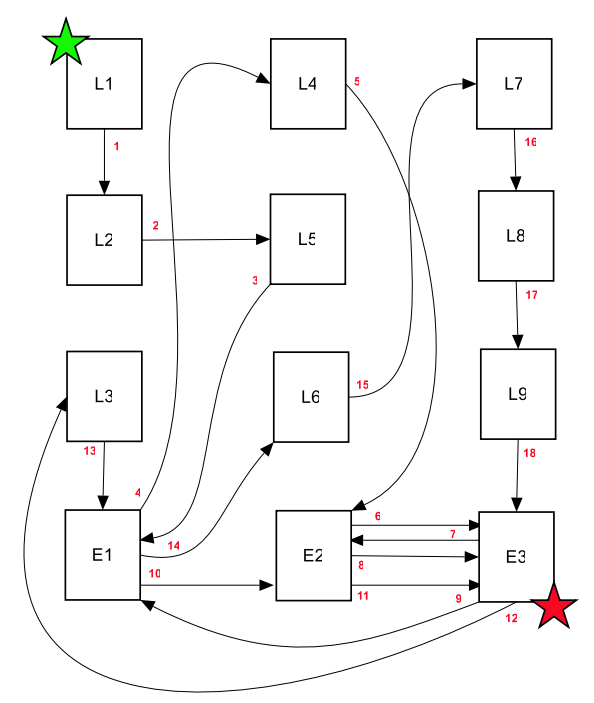

6(c)

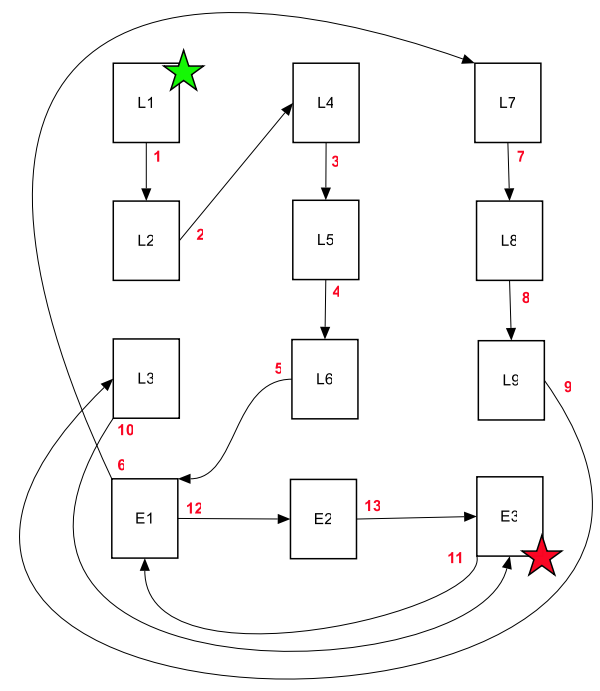

$6(d)$

Fig. 6. PPTs' Learning Behavior in Serial Group (a) and Random Group (b), (c) and (d), Green Star (Start), Red Star (Stop) 
The difference between this research and the research in the field of sports education is in the domain of learning outcomes. In the field of sports education, the learning outcome is targeted in the psychomotor domain, which is generally known as skill. There are relatively few skills practiced, so that each session presents the same alternative skills, but only in different order variations, and the learning setting that is designed is also still conventional. While the OG application developed in this research targeted in the cognitive domain, there are quite a lot of concepts that must be mastered by PPTs, so that each session presents a different sub-topic, and the learning setting is designed to be ICT-based so that monitoring and assessment is done automatically.

Based on the posttest results, the PPTs' concept mastery who was using OG application in the serial and random group could still be improved (42\% for serial group and $49 \%$ for random group). These results are possibly related to the characteristics of PPTs at the research location. Nonetheless, this research has shown that through the setting variations of PPTs' access to sub-topics of interference and diffraction, two ICT-based gamification-application models are found, namely the serial model and the random model. The setting variations of PPTs' access has an impact on the variety of the ways they learn, especially in the random model that is seen as having the potential to develop critical and creative thinking skills while interacting with the OG application. These two skills are very important for the PPTs [88, 89], but to present empirical evidence related to this, further research is certainly needed. For further research, through setting variations of PPTs' access in ICT-based gamificationapplications, there may be possibilities that other models besides the serial and random models will be found. In addition, this research has opened new insights in tracing the effect of contextual interference, especially on cognitive domain learning outcomes.

\section{Conclusion}

The setting variations of PPTs' access for each level and evaluation have resulted in two OG application models, namely the serial and random model. The OG with serial model has succeeded in presenting sub-topics of learning material sequentially in each session. The OG with random model has succeeded in giving PPTs free access to each sub-topic and evaluation so that they can learn these sub-topics randomly in an order of their choosing. There is no significant difference in the improvement of PPTs' concept mastery between the serial and random model. Both of these models can be used as alternatives that can be used in designing ICT-based gamification-applications for more effective and efficient learning in the future.

\section{Acknowledgements}

The authors convey gratitude to parties that contributes and helps in the process of conducting this research. Appreciation and gratitude conveyed for; 1) LPDP (Lem- 
baga Pengelola Dana Pendidikan), BUDI-DN as the main sponsor of this research, and 2) Lecturers and PPTs who participated in this research.

\section{References}

[1] Deterding, S., Dixon, D., Khaled, R., \& Nacke, L. (2011). From Game Design Elements to Gamefulness: Defining Gamification. Proceedings of the 15th international Academic MindTrek Conference: Envisioning Future Media Environments, pp. 9-15. https://doi.org/ $\underline{10.1145 / 2181037.2181040}$

[2] Deterding, S. (2012). Gamification: Designing for Motivation. Interactions, 19(4), 14-17.

[3] Mulyana, A., Hindersah, H., \& Prihatmanto, A. S. (2015, December). Gamification design of traffic data collection through social reporting. In 2015 4th International Conference on Interactive Digital Media (ICIDM) (pp. 1-4). IEEE. https://doi.org/10.1109/IDM.2015.75 $\underline{16315}$

[4] Hindersah, H., \& Prihatmanto, A. S. (2015, December). Designing gamification for taxi booking system (Case study: Bandung smart transportation system). In 2015 4th International Conference on Interactive Digital Media (ICIDM) (pp. 1-6). IEEE. https:// doi.org/10.1109/IDM.2015.7516316

[5] Lieberoth, A., Jensen, N. H., \& Bredahl, T. (2018). Selective psychological effects of nudging, gamification and rational information in converting commuters from cars to buses: A controlled field experiment. Transportation research part F: traffic psychology and behaviour, 55, 246-261. https://doi.org/10.1016/j.trf.2018.02.016

[6] Marcucci, E., Gatta, V., \& Le Pira, M. (2018). Gamification design to foster stakeholder engagement and behavior change: An application to urban freight transport. Transportation Research Part A: Policy and Practice, 118, 119-132. https://doi. org/10.1016/j.tra.2018.08.028

[7] Drakoulis, R., Bellotti, F., Bakas, I., Berta, R., Paranthaman, P. K., Dange, G. R., ... \& Amditis, A. (2018). A gamified flexible transportation service for on-demand public transport. IEEE Transactions on Intelligent Transportation Systems, 19(3), 921-933. https ://doi.org/10.1109/tits.2018.2791643

[8] Olszewski, R., Pałka, P., \& Turek, A. (2018). Solving "Smart City" Transport Problems by Designing Carpooling Gamification Schemes with Multi-Agent Systems: The Case of the So-Called "Mordor of Warsaw". Sensors, 18(1), 141. https://doi.org/10.3390/s18010141

[9] Alemán, J. J., Sanchez-Pi, N., Martí, L., Molina, J. M., \& García, A. C. B. (2016, July). Gamification and information fusion for rehabilitation: An ambient assisted living case study. In International Conference on Human Aspects of IT for the Aged Population (pp. 16-25). Springer, Cham. https://doi.org/10.1007/978-3-319-39949-2_2

[10] Maturo, A., \& Setiffi, F. (2016). The gamification of risk: how health apps foster selfconfidence and why this is not enough. Health, Risk \& Society, 17(7-8), 477-494. https:// doi.org/10.1080/13698575.2015.1136599

[11] González, C. S., Gómez, N., Navarro, V., Cairós, M., Quirce, C., Toledo, P., \& MarreroGordillo, N. (2016). Learning healthy lifestyles through active videogames, motor games and the gamification of educational activities. Computers in Human Behavior, 55, 529551. https://doi.org/10.1016/j.chb.2015.08.052

[12] Pinto, J. F., Carvalho, H. R., Chambel, G. R., Ramiro, J., \& Goncalves, A. (2018, May). Adaptive gameplay and difficulty adjustment in a gamified upper-limb rehabilitation. In 2018 IEEE 6th International Conference on Serious Games and Applications for Health (SeGAH) (pp. 1-8). IEEE. https://doi.org/10.1109/SeGAH.2018.8401363 
[13] Lucassen, G., \& Jansen, S. (2014). Gamification in Consumer Marketing-Future or Fallacy?. Procedia-Social and Behavioral Sciences, 148, 194-202. https://doi.org/10.1016/ j.sbspro.2014.07.034

[14] Rodrigues, L. F., Oliveira, A., \& Costa, C. J. (2016). Playing seriously-How gamification and social cues influence bank customers to use gamified e-business applications. Computers in human behavior, 63, 392-407. https://doi.org/10.1016/j.chb.20 16.05 .063

[15] Hsu, C. L., \& Chen, M. C. (2018). How gamification marketing activities motivate desirable consumer behaviors: Focusing on the role of brand love. Computers in Human Behavior, 88, 121-133. https://doi.org/10.1016/j.chb.2018.06.037

[16] Parapanos, D., \& Michopoulou, E. E. (2019). Understanding Key Motivations for Using a Hotel Gamified Application. In Information and Communication Technologies in Tourism 2019(pp. 411-422). Springer, Cham. https://doi.org/10.1007/978-3-030-05940-8_32

[17] Frisiello, A., Nguyen, Q. N., \& Rossi, C. (2017, December). Gamified crowdsourcing for disaster risk management. In 2017 IEEE International Conference on Big Data (Big Data) (pp. 3727-3733). IEEE. https://doi.org/10.1109/BigData.2017.8258370

[18] Love, S. M., Sanders, M. R., Turner, K. M., Maurange, M., Knott, T., Prinz, R., ... \& Ainsworth, A. T. (2016). Social media and gamification: Engaging vulnerable parents in an online evidence-based parenting program. Child abuse \& neglect, 53, 95-107. https:// doi.org/10.1016/i.chiabu.2015.10.031

[19] Su, C. H., \& Cheng, C. H. (2015). A mobile gamification learning system for improving the learning motivation and achievements. Journal of Computer Assisted Learning, 31(3), 268-286. https://doi.org/10.1111/jcal.12088

[20] Rose, J. A., O’Meara, J. M., Gerhardt, T. C., \& Williams, M. (2016). Gamification: using elements of video games to improve engagement in an undergraduate physics class. Physics Education, 51(5), 055007. https://doi.org/10.1088/0031-9120/51/5/055007

[21] Poondej, C., \& Lerdpornkulrat, T. (2016). The development of gamified learning activities to increase student engagement in learning. Australian Educational Computing, 31(2).

[22] Kusuma, G. P., Wigati, E. K., Utomo, Y., \& Suryapranata, L. K. P. (2018). Analysis of gamification models in education using MDA framework. Procedia Computer Science, 135, 385-392. https://doi.org/10.1016/j.procs.2018.08.187

[23] Panthalookaran, V. (2018, April). Gamification of physics themes to nurture engineering professional and life skills. In 2018 IEEE Global Engineering Education Conference (EDUCON) (pp. 931-939). IEEE. https://doi.org/10.1109/EDUCON.2018.8363330

[24] Göksün, D. O., \& Gürsoy, G. (2019). Comparing success and engagement in gamified learning experiences via Kahoot and Quizizz. Computers \& Education, 135, 15-29. https:// doi.org/10.1016/j.compedu.2019.02.015

[25] O'Donovan, S., Gain, J., \& Marais, P. (2013, October). A case study in the gamification of a university-level games development course. In Proceedings of the South African Institute for Computer Scientists and Information Technologists Conference (pp. 242-251). ACM. https://doi.org/10.1145/2513456.2513469

[26] DomíNguez, A., Saenz-De-Navarrete, J., De-Marcos, L., FernáNdez-Sanz, L., PagéS, C., \& MartíNez-Herrálz, J. J. (2013). Gamifying learning experiences: Practical implications and outcomes. Computers \& Education, 63, 380-392. https://doi.org/10.1016/j.compedu.20 $\underline{12.12 .020}$

[27] Abramovich, S., Schunn, C., \& Higashi, R. M. (2013). Are badges useful in education?: It depends upon the type of badge and expertise of learner. Educational Technology Research and Development, 61(2), 217-232. https://doi.org/10.1007/s11423-013-9289-2 
[28] Barata, G., Gama, S., Jorge, J., \& Gonçalves, D. (2013, October). Improving participation and learning with gamification. In Proceedings of the First International Conference on gameful design, research, and applications (pp. 10-17). ACM. http://dx.doi.org/10.1145/2 583008.2583010

[29] Gibbons, T. E. (2013). COR: A new course framework based on elements of game design. In W. D. Armitage (Ed.), Proceedings of 14th Annual Conference in Information Technology Education (SIGITE) (pp. 77-82). Orlando, FL: ACM. https://doi.org/10.1145/ 2512276.2512292

[30] Goehle, G. (2013). Gamification and web-based homework. Primus, 23(3), 234-246. https ://doi.org/10.1080/10511970.2012.736451

[31] Gordon, N., Brayshaw, M., \& Grey, S. (2013). Maximising gain for minimal pain: Utilising natural game mechanics. Innovation in Teaching and Learning in Information and Computer Sciences, 12(1), 27-38. https://doi.org/10.11120/ital.2013.00004

[32] Bartel, A., \& Hagel, G. (2014). Engaging students with a mobile game-based learning system in university education. International Journal of Interactive Mobile Technologies, 8(4), 957-960. https://doi.org/10.3991/ijim.v8i4.3991

[33] De-Marcos, L., Domínguez, A., Saenz-de-Navarrete, J., \& Pagés, C. (2014). An empirical study comparing gamification and social networking on e-learning. Computers \& Education, 75, 82-91. https://doi.org/10.1016/j.compedu.2014.01.012

[34] Haaranen, L., Ihantola, P., Hakulinen, L., \& Korhonen, A. (2014, March). How (not) to introduce badges to online exercises. In Proceedings of the 45th ACM technical symposium on Computer science education (pp. 33-38). ACM. https://doi.org/10.1145/25 38862.2538921

[35] Pirker, J., Riffnaller-Schiefer, M., \& Gütl, C. (2014, June). Motivational active learning: engaging university students in computer science education. In Proceedings of the 2014 conference on Innovation \& technology in computer science education (pp. 297-302). ACM. https://doi.org/10.1145/2591708.2591750

[36] Lam, Y. W., Hew, K. F., \& Chiu, K. F. (2017). Improving argumentative writing: Effects of a blended learning approach and gamification. Language Learning \& Technology, 22(1), 97-118. https://dx.doi.org/10125/44583

[37] Mese, C., \& Dursun, O. O. (2019). Effectiveness of Gamification Elements in Blended Learning Environments. Turkish Online Journal of Distance Education (TOJDE), 20(3), 119-142. https://doi.org/10.17718/tojde.601914

[38] Burkey, D. D., Anastasio, M. D. D., \& Suresh, A. (2013). Improving student attitudes toward the capstone laboratory course using gamification. Proceedings of 2013 Annual Conference and Exposition of the American Society for Engineering Education, (pp. 39503968). Atlanta, GA: ASEE.

[39] Iosup, A., \& Epema, D. (2014, March). An experience report on using gamification in technical higher education. In Proceedings of the 45th ACM technical symposium on Computer science education (pp. 27-32). ACM. https://doi.org/10.1145/2538862.2538899

[40] Li, W., Grossman, T., \& Fitzmaurice, G. (2012, October). GamiCAD: a gamified tutorial system for first time autocad users. In Proceedings of the 25th annual ACM symposium on User interface software and technology (pp. 103-112). ACM. https://doi.org/10.1145/238 $\underline{0116.2380131}$

[41] Urh, M., Vukovic, G., \& Jereb, E. (2015). The model for introduction of gamification into e-learning in higher education. Procedia-Social and Behavioral Sciences, 197, 388-397. https://doi.org/10.1016/j.sbspro.2015.07.154

[42] Hakulinen, L., Auvinen, T., \& Korhonen, A. (2015). The effect of achievement badges on students' behavior: An empirical study in a university-level computer science 
course. International Journal of Emerging Technologies in Learning (iJET), 10(1), 18-29. https://doi.org/10.3991/ijet.v10i1.4221

[43] Hamzah, W. M. A. F. W., Ali, N. H., Saman, M. Y. M., Yusoff, M. H., \& Yacob, A. (2015). Influence of gamification on students' motivation in using e-learning applications based on the motivational design model. International Journal of Emerging Technologies in Learning (iJET), 10(2), 30-34. https://doi.org/10.3991/ijet.v10i2.4355

[44] Kristiadi, D., \& Mustofa, K. (2017). Platform Gamifikasi untuk Perkuliahan. IJCCS (Indonesian Journal of Computing and Cybernetics Systems), 11(2), 131-142. https://doi. org/10.22146/ijccs. 17053

[45] Gañán, D., Caballé, S., Clarisó, R., Conesa, J., \& Bañeres, D. (2017). ICT-FLAG: a webbased e-assessment platform featuring learning analytics and gamification. International Journal of Web Information Systems, 13(1), 25-54. https://doi.org/10.1108/IJWIS-12-20 16-0074

[46] Bernik, A., Radošević, D., \& Bubaš, G. (2017, May). Introducing gamification into elearning university courses. In 2017 40th International Convention on Information and Communication Technology, Electronics and Microelectronics (MIPRO) (pp. 711-716). IEEE. https://doi.org/10.23919/MIPRO.2017.7973515

[47] Barna B., Fodor S. (2018) An Empirical Study on the Use of Gamification on IT Courses at Higher Education. In: Auer M., Guralnick D., Simonics I. (eds) Teaching and Learning in a Digital World. ICL 2017. Advances in Intelligent Systems and Computing, vol 715. Springer, Cham. https://doi.org/10.1007/978-3-319-73210-7 80

[48] Bernik, A., Bubaš, G., \& Radošević, D. (2018, May). Measurement of the effects of elearning courses gamification on motivation and satisfaction of students. In 201841 st International Convention on Information and Communication Technology, Electronics and Microelectronics (MIPRO) (pp. 0806-0811). IEEE. https://doi.org/10.23919/MIPRO.2018. $\underline{8400149}$

[49] Hassan, M. A., Habiba, U., Majeed, F., \& Shoaib, M. (2019). Adaptive gamification in elearning based on students' learning styles. Interactive Learning Environments, 1-21. https ://doi.org/10.1080/10494820.2019.1588745

[50] SobodiÄ, A., Balaban, I., \& Kermek, D. (2018). Usability Metrics for Gamified E-learning Course: A Multilevel Approach. International Journal of Emerging Technologies in Learning (iJET), 13(5), 41-55. https://doi.org/10.3991/ijet.v13i05.8425

[51] Gené, O. B., Núñez, M. M., \& Blanco, Á. F. (2014, October). Gamification in MOOC: challenges, opportunities and proposals for advancing MOOC model. In Proceedings of the Second International Conference on Technological Ecosystems for Enhancing Multiculturality (pp. 215-220). ACM. https://doi.org/10.1145/2669711.2669902

[52] Vaibhav, A., \& Gupta, P. (2014, December). Gamification of MOOCs for increasing user engagement. In 2014 IEEE International Conference on MOOC, Innovation and Technology in Education (MITE) (pp. 290-295). IEEE. https://doi.org/10.1109/MITE.2014.702029 $\underline{0}$

[53] Hentenryck, P. V., \& Coffrin, C. (2014). Teaching creative problem solving in a MOOC. In J. Dougherty, \& K. Nagel (Eds.), Special Interest Group on Computer Science Education 2014 (pp. 677-682). Atlanta, GA: ACM. https://doi.org/10.1145/2538862.2538913

[54] Chang, J. W., \& Wei, H. Y. (2016). Exploring engaging gamification mechanics in massive online open courses. Journal of Educational Technology \& Society, 19(2), 177-203.

[55] Antonaci, A., Klemke, R., Stracke, C. M., \& Specht, M. (2017, April). Gamification in MOOCs to enhance users' goal achievement. In 2017 IEEE Global Engineering Education Conference (EDUCON) (pp. 1654-1662). IEEE. https://doi.org/10.1109/EDUCON.2017. $\underline{7943070}$ 
[56] Zhu Y., Pei L., Shang J. (2017) Improving Video Engagement by Gamification: A Proposed Design of MOOC Videos. In: Cheung S., Kwok L., Ma W., Lee LK., Yang H. (eds) Blended Learning. New Challenges and Innovative Practices. ICBL 2017. Lecture Notes in Computer Science, vol 10309. pp. 433-444. Springer, Cham. https:// doi.org/10.1007/978-3-319-59360-9_38

[57] Abu Bakar N.F., Yusof A.F., A. Iahad N., Ahmad N. (2018) The Implementation of Gamification in Massive Open Online Courses (MOOC) Platform. In: Abdullah N., Wan Adnan W., Foth M. (eds) User Science and Engineering. i-USEr 2018. Communications in Computer and Information Science, vol 886. Springer, Singapore. https://doi.org/10.1007/978-981-13-1628-9 17

[58] Klemke, R., Eradze, M., \& Antonaci, A. (2018). The flipped MOOC: using gamification and learning analytics in MOOC design — a conceptual approach. Education Sciences, 8(1), 25. https://doi.org/10.3390/educsci8010025

[59] Ortega-Arranz, A., Er, E., Martínez-Monés, A., Bote-Lorenzo, M. L., Asensio-Pérez, J. I., \& Muñoz-Cristóbal, J. A. (2019). Understanding student behavior and perceptions toward earning badges in a gamified MOOC. Universal Access in the Information Society, 18(3), 533-549. https://doi.org/10.1007/s10209-019-00677-8

[60] Chen, Y., Burton, T., Mihaela, V., \& Whittinghill, D. M. (2015). Cogent: A Case Study of Meaningful Gamification in Education with Virtual Currency. International Journal of Emerging Technologies in Learning, 10(1), 39-45. http://doi.org/10.3991/ijet.v10i1.4247

[61] Mekler, E. D., Brühlmann, F., Tuch, A. N., \& Opwis, K. (2017). Towards understanding the effects of individual gamification elements on intrinsic motivation and performance. Computers in Human Behavior, 71, 525-534. https://doi.org/10.1016/j.chb.2015. $\underline{08.048}$

[62] Khalil, M., Ebner, M., \& Admiraal, W. (2017). How can Gamification Improve MOOC Student Engagement? In Proceedings of the 11th European Conference on Games Based Learning: ECGBL 2017 (pp. 819-828).

[63] Kyewski, E., \& Krämer, N. C. (2018). To gamify or not to gamify? An experimental field study of the influence of badges on motivation, activity, and performance in an online learning course. Computers \& Education, 118, 25-37. https://doi.org/10.1016/j.compedu. 2017.11.006

[64] Bicen, H., \& Kocakoyun, S. (2018). Perceptions of Students for Gamification Approach: Kahoot as a Case Study. International Journal of Emerging Technologies in Learning, 13(2), 72-93. https://doi.org/10.3991/ijet.v13i02.7467

[65] Khouna, J., Ajana, L., Rhazal, A., \& El Mokri, A. (2019). Are Educational Games Engaging and Motivating Moroccan Students to Learn Physics? An Experimental Study. International Journal of Emerging Technologies in Learning, 14(16). 66-82. https:// doi.org/10.3991/ijet.v14i16.10641

[66] Hursen, C., \& Bas, C. (2019). Use of Gamification Applications in Science Education. International Journal of Emerging Technologies in Learning, 14(1). 4-23. https://doi. org/10.3991/ijet.v14i01.8894

[67] Wardani, I., Tolle, H., \& Aknuranda, I. (2019). Evaluation of An Educational Media on Cube Nets Based on Learning Effectiveness and Gamification Parameters. International Journal of Emerging Technologies in Learning, 14(14). https://doi.org/10.3991/ijet.v14i14. $\underline{10505}$

[68] Flores, E. G. R., Montoya, M. S. R., \& Mena, J. (2016, November). Challenge-based gamification and its impact in teaching mathematical modeling. In Proceedings of the Fourth International Conference on Technological Ecosystems for Enhancing Multiculturality (pp. 771-776). ACM. https://doi.org/10.1145/3012430.3012605 
[69] Hew, K. F., Huang, B., Chu, K. W. S., \& Chiu, D. K. (2016). Engaging Asian students through game mechanics: Findings from two experiment studies. Computers \& Education, 92-93, 221-236. https://doi.org/10.1016/j.compedu.2015.10.010

[70] Ros-Morente, A., Cabello Cuenca, E., \& Filella-Guiu, G. (2018). Analysis of the Effects of two Gamified Emotional Education Software's in Emotional and Well-being Variables in Spanish Children and Adolescents. International Journal of Emerging Technologies in Learning, 13(9), 148-159. https://doi.org/10.3991/ijet.v13i09.7841

[71] Wang, F., Wang, Y., \& Hu, X. (2017). Gamification Teaching Reform for Higher Vocational Education in China: A Case Study on Layout and Management of Distribution Center. International Journal of Emerging Technologies in Learning (iJET), 12(09), 130-144. https://doi.org/10.3991/ijet.v12.i09.7493

[72] Dahar, R. W. (2011). Teori-Teori Belajar dan Pembelajaran. Jakarta : Erlangga

[73] Schunk, D. H. (2012). Learning Theories an Educational Perspective, Sixth Edition (Teoriteori Pembelajaran: Perspektif Pendidikan). Pustaka Pelajar: Yogyakarta

[74] Ausubel, D. P. (1968). Educational Psychology. A Cognitive View. New York: Holt, Rinehart, and Winston

[75] Novak, J. D. (1977). A theory of education. Ithaca, NY: Cornell University Press.

[76] Arif, Z. (2012). Andragogi. Bandung: PT Angkasa

[77] Dharma, A. D. S. (2015). Keberagaman Pengaturan Batas Usia Dewasa Seseorang untuk Melakukan Perbuatan Hukum dalam Peraturan Perundang-undangan di Indonesia. Repertorium, 2(2), $168-176$.

[78] Tarno, H. (2017). Pendidikan Orang Dewasa (POD). Yogyakarta: Gava Media

[79] Saprudin, S., Liliasari, L., \& Prihatmanto, A. S. (2017, September). Pre-Service Physics Teachers' Concept Mastery and the Challenges of Game Development on Physics Learning. In Journal of Physics: Conference Series (Vol. 895, No. 1, p. 012109). IOP Publishing. https://doi.org/10.1088/1742-6596/895/1/012109

[80] Wiersma, W \& Jurs, S. G. (2009). Research Methods in Education an introduction Ninth Edition. United States of America: Pearson Education, Inc.

[81] Hake, R. R. (1998). Interactive-engagement versus traditional methods: A six-thousandstudent survey of mechanics test data for introductory physics courses. American journal of Physics, 66(1), 64-74. http://doi.org/10.1119/1.18809

[82] Magill, R. A., \& Anderson, D. I. (2014). Motor learning and control: Concepts and applications (Vol. 11). New York: McGraw-Hill.

[83] Goode, S., \& Magill, R. A. (1986). Contextual interference effects in learning three badminton serves. Research quarterly for exercise and sport, 57(4), 308-314. http://doi. org/10.1080/02701367.1986.10608091

[84] Porter, J. M., \& Magill, R. A. (2010). Systematically increasing contextual interference is beneficial for learning sport skills. Journal of sports sciences, 28(12), 1277-1285. https:// doi.org/10.1080/02640414.2010.502946

[85] Rad, L. S., Babolhavaeji, F., \& Babolhavaeji, E. (2012). A comparison of blocked and random practice on acquisition of swimming skills. European Journal of Experimental Biology, 2(6), 2073-2076.

[86] Aiken, C. A., \& Genter, A. M. (2018). The effects of blocked and random practice on the learning of three variations of the golf chip shot. International Journal of Performance Analysis in Sport, 18(2), 339-349. https://doi.org/10.1080/24748668.2018.1475199

[87] Fazeli, D., Taheri, H., \& Saberi Kakhki, A. (2017). Random versus blocked practice to enhance mental representation in golf putting. Perceptual and motor skills, 124(3), 674-688. https://doi.org/10.1177/0031512517704106 
[88] Saprudin, S., Liliasari, S., Prihatmanto, A. S., \& Setiawan, A. (2019, February). Profile of pre-service physics teachers' creative thinking skills on wave and optics course. In Journal of Physics: Conference Series (Vol. 1157, No. 3, p. 032030). IOP Publishing. https://doi. org/10.1088/1742-6596/1157/3/032030

[89] Saprudin, S., Liliasari, S., Prihatmanto, A. S., \& Setiawan, A. (2019, February). Preservice physics teachers' thinking styles and its relationship with critical thinking skills on learning interference and diffraction. In Journal of Physics: Conference Series (Vol. 1157, No. 3, p. 032029). IOP Publishing. https://doi.org/10.1088/1742-6596/1157/3/032029

\section{Authors}

Saprudin Saprudin is a doctoral student at Science Education Study Program, School of Post Graduates, Universitas Pendidikan Indonesia. He also works as an associate professor at Physics Education Study Program, Universitas Khairun, Ternate, Indonesia.

Liliasari Liliasari works as a professor in Science Education Study Program, School of Post-Graduates, Universitas Pendidikan Indonesia, Bandung, Indonesia. Her research mostly focused on the improvement of students' concept mastery and higher order thinking skills in science education.

Ary Setijadi Prihatmanto is an associate professor at Sekolah Tinggi Elektro dan Informatika Institut Teknologi Bandung (STEI ITB). He is also Director of Pusat Penelitian Teknologi Informasi dan Komunikasi ITB (2015-present), an expert of Southeast Asian Ministry of Education on Open Learning Center (SEAMOLEC) (2015), and Director of Indonesia Digital Media Forum (2013-2015).

Andhy Setiawan is an associate professor at Physics Study Program, Universitas Pendidikan Indonesia, Bandung, Indonesia. He is also the lecturer in waves and optics course on Physics Study Program.

Article submitted 2019-09-27. Resubmitted 2020-01-30. Final acceptance 2020-01-30. Final version published as submitted by the authors. 